\title{
Quality Assurance and Higher Fashion Education in Ghana: Examining the Contemporary Quandary
}

\author{
Joana Akweley Adotey ${ }^{1}$, Elizabeth Obinnim², Ninette Afi Pongo ${ }^{3, *}$ \\ ${ }^{1}$ Department of Fashion Designing and Textiles Studies, Tamale Technical University, Tamale, Ghana \\ ${ }^{2}$ Department of Fashion Design and Textiles, Ho Technical University, Ho, Ghana \\ ${ }^{3}$ Department of Fashion Design and Textiles Education, University of Education, Winneba, Kumasi, Ghana
}

\section{Email address:}

adotey1985@gmail.com (J. A. Adotey), edobinnim@gmail.com (E. Obinnim), afienyonam@yahoo.com (N. A. Pongo)

${ }^{*}$ Corresponding author

\section{To cite this article:}

Joana Akweley Adotey, Elizabeth Obinnim, Ninette Afi Pongo. Quality Assurance and Higher Fashion Education in Ghana: Examining the Contemporary Quandary. International Journal of Vocational Education and Training Research. Vol. 2, No. 6, 2016, pp. 39-48. doi: $10.11648 /$ j.ijvetr.20160206.12

Received: December 2, 2016; Accepted: December 24, 2016; Published: January 16, 2017

\begin{abstract}
Since the 1990s, quality and quality assurance have become the key themes of higher education institutions almost universally. Issues have been raised about the output of higher education institutions and whether communities are receiving real value for their investments. Although situations vary from country to country, some far-reaching developments have contributed to growing interest in setting up policy mechanisms to ensure quality and accountability in higher education. Of particular significance is the trend towards mass higher education. This paper hence, evaluated quality assurance in the Ghanaian higher fashion education context. It explored issues within the area of quality of higher fashion education in Ghana and other parts of the developing world. A mixed methods design was used to obtain the views of respondents. Interview and questionnaires were the main research instruments employed for data collection. The study analysed the opinions of both staff and students in some higher education institutions. The study revealed that establishing quality assurance systems and policies is not a guarantee to solving quality issues in higher fashion education.
\end{abstract}

Keywords: Quality Assurance, Higher Fashion Education, Ghanaian Higher Education

\section{Introduction}

Sustainable development that is an advancement that meets the needs of the 21 st century and beyond through the provision of quality Higher Education (HE) has posed serious concerns to educational banners and stakeholders [1]. These concerned groups are worried as HE has not categorically brought about the changes in knowledge, values, behaviours and lifestyles required to overcome the challenges of the present. Since the 1990s, quality and quality assurance have become the key themes for higher education the world over [2]. Concerns have been raised about the output from higher education institutions. Though circumstances vary from country to country, several broad trends are contributing to the increasing interest in establishing mechanisms to ensure the quality of higher education.

This century is beholding a new relationship between knowledge and economy, where a nation's capacity to generate quality knowledge coupled with skilled human resources is increasingly linked with its ability to create wealth. This is conceivable if a country has quality assured as well as a well-developed education system. The education process is no longer the same today given the advances in technology that has overcome geographical boundaries. Consequently, public awareness and aspirations of the knowledge linked economy are on the rise and employers are increasingly seeking highly qualified workforce.

African and specifically Ghanaian higher education are facing all these challenges. On the one hand, the nation has institutions comparable in facilities and quality to any top institution at the international level, and, on the other hand, institutions that are weak in infrastructure and quality. The 
government has largely funded higher education. The concern for quality assurance is linked to the growing Ghanaian economy, which is not corresponding to the education systems. Simply put, the current higher education system is not entirely market driven.

Current debates on quality in higher education in Ghana, for instance, focus mainly on more advanced systems and separate elements of the system. Most of the current quality assurance research focuses on how government policies have impacted quality assurance in Ghana. Including quality assurance in distance learning, quality assurance in students' academic assessment, the accreditation process and how it has influenced the quality of the sector $[3,4,5,6,7]$. Research, which addresses higher education quality assurance in a holistic way, is uncommon. As a result, Baryeh Obeng (2009) claims that the current debate in quality assurance of higher education does not adequately lead to developing quality assurance measures.

Another observation is that researchers, as Pillay \& Kimber (2009) point out, measure the quality of higher education against a global agenda, including global higher education rankings. Identifying this anomaly in the current debate on higher quality education, this research sought to develop an alternate model for higher education quality assurance for Ghana. This is an alternative to pursuing a position in a global system that can have limited significance to the local higher education context. Too little is available in the literature on what African nations are doing to control and advance higher education quality, what it takes to carry out these initiatives and what has been the effect [10].

Within the last decade alone, many nations have witnessed unbelievable growth in enrolment, and in most nations, it has increased over five times [11]. Ghana is no exception. With the advancement of mass higher education, a greater variety of educational offerings has appeared. Various kinds of institutions have been established, offering a variety of study programs and methods of instructional delivery as a means of accommodating the rapid enrolment expansion and the growing demand for higher education. Another is the accelerated growth of the private sector in higher education. In some countries, it amounts to approximately $30 \%$ of the students enroled in institutions of higher learning [2].

In the face of this increasing enrolment in higher education including fashion design - Global enrolment in 2000 was 97 million; in 2011, it was 165 million. It is estimated this will reach 263 million by 2025 [12] and over four-fold between 1985 and 2005 in sub-Saharan Africa. With these developing and continuously growing systems of higher education, quality assurance is becoming a central concern. Within countries, a persistent debate about whether new forms of quality assurance for higher education are needed, and what approaches would be most useful.

In Africa, higher education is growing at a fast rate, yet as [13] puts it, expanded access has failed to be matched by an improvement in quality. Also as [14] points out, quality assurance in higher fashion education is not a thoroughly investigated area within the context of developing countries in Sub - Saharan Africa. Much of the research have been dominated by the United Kindom (UK) and the United States of America (US). In the Ghanaian context, studies on higher fashion education are under-represented in literature and are generally being overlooked and hence remains a blind spot. The need to have a quality assurance framework that is coherent and consistent with the goals of higher fashion education in Ghana is, therefore, a must.

\section{Literature Review}

\subsection{The Importance of Quality Assurance in Higher Education in Africa}

Undeniably, there is an unmistakably strong correlation between participation in higher education and a country's level of development [15]. Higher education is crucial to economic success and long-term development of any nation, especially in Africa, a continent facing several challenges of social progress, economic growth, and technological advancement on many fronts.

Consequently, there is a widespread and legitimate concern regarding Africa, not only by Africans themselves but the global community as well. Africa is the single continent in the world where, according to [16], while the rest of the global economy increased at an annual rate of 2 percent from 1960 to 2002, growth performance in Africa has been dismal. From 1974 through to the middle of the 1990s, growth was negative, reaching negative 1.5 percent in 1990-4. As a result, hundreds of millions of African citizens have become poorer; one-half of the people on the African continent lives below the poverty line. In sub-Saharan Africa, per capita Gross Domestic Product (GDP) is now less than it was in 1974, having declined by 11 percent.

In 1970, one in ten needy citizens in the world lived in Africa; by 2000, the figure was nearer to one in two. That trend transposes into 360 million poor Africans in 2000, as compared to 140 million in 1975 [17]. The challenge for Africa is the capability to develop an HE sector that can aid the region in reconciling these ostensibly contradictory missions - to be locally relevant and globally attractive and competitive, hence the importance of quality assurance in higher education.

However, quality assurance in higher education is a relatively new phenomenon in Africa. Though it is developing rapidly, it is still in the formative stages in many countries. For instance, by 2013 only 21 out of 55 countries in sub-Saharan Africa had national quality assurance agencies in place, most of them recently set up [18]. These agencies have been set-up essentially to control the development of higher education provision, particularly by the private sector, rather than assuring accountability or advancing quality. Quality performance of higher education institutions is necessary as it contributes to economic progress, has social and political benefits, aids in human capital and professional development, helps in knowledge generation and adaptation through research and innovation, 
supports linkage to the world of work and promotes international cooperation through high-level relevant workforce training.

The level of diligence and demand for quality checks in and of the higher education sector has traditionally been of less concern or even of minimal interest. This may be attributed to the fact that, compared with secondary level education, not everyone is required to participate. Also, tertiary level education concerns legal adults and it can reasonably be considered that they make their own 'consumer choices' at their risk. Additionally, teachers at the third level of learning are deemed to be of the highest calibre purporting a de-facto high quality of provision. Presently, it is this interpretation of quality of a "quality higher education" that has proved to be so polarising [18].

\subsection{Measuring Quality Assurance in Higher Education}

Quality in higher education is challenging to measure [19]. Weber (2010) emphasises that unlike the manufacturing industry, the production function in education is incredibly complicated, and outcomes are most often not easily perceptible in a timely, objective or useful fashion. The area of quality assurance in higher education is still in its youthful phase, with varying and changing procedures and uncertainty in both aims and terminology. Productivity measure comprises a conceptually simplistic framework. Nevertheless, in the case of higher education, complexities are formulated by some factors; institutions of higher education are multi-product firms; inputs and outputs of the productive process are heterogeneous, involving non-market variables, and are dependent on quality shifts and temporal variations; measurement is impeded by gaps in needed data. None of these complexities is unique to higher education, but their severity and number may be [20].

Again, [21] emphasises that measuring the output of education is really hard. More importantly, the output of educational institutions is hard to measure since they are multi-product organisations. They do not provide only education; they offer additional services as well. [22] provide an excellent description of the multi-product nature of higher education institutions. Also, the inputs and outputs of higher education display widely varying characteristics. The abilities of students and teachers vary, as do their levels of preparedness and effectiveness in teaching and learning.

\subsection{A Novel Form of Quality Assurance}

The combined effects of globalisation and 'massification' have radically altered the traditional way HE institutions are perceived and managed. The competitive forces unleashed by globalisation and massification have forced higher education institutions to become more receptive to the fast-changing labour markets and student program interests. These are motivating policy makers to pursue innovative ways for assuring academic quality in higher education [23]. Consequently, institutions in many countries have attempted increased flexibility and autonomy from traditional state quality assurance regulations so that they can respond more quickly to changing social demands by establishing new academic programs, reconfiguring existing ones and eliminate outdated curricula.

The application of quality assurance in higher education, while maintaining the same basic goals of defining and recognising quality, is to some degree complicated by the socio-economic role education plays in developing local, national and global societies. The integration of quality assurance philosophies into higher education have become a global issue. This move towards integrating quality assurance into higher education has benefited institutions and students as it improves the quality, transparency and comparability of degrees.

\subsection{The Importance of Enforcing Quality in Higher Education Institutions in Ghana}

According to [24], the presence of heterogeneity of quality policies, schemes and their different degree of structuration in the various national contexts, the semi-institutionalization of quality assurance that exposes it to a certain degree of contention and, above all, the emphasis placed on systems' and institutions' accountability give rise to some problems, tensions and contradictions in the practice of quality assessment. Ghana is no exception in terms of these issues.

A few decades ago, it was taken for granted that university staff should be formally and frequently assessed, except when they were candidates for promotion. Most Universities saw this as a task that had to be done by peers, with other stakeholders seldom being included in this process. These have now changed completely. There are probably very few HE institutions now where there is no formal appraisal of teaching and research systems of the staff by peers and/or students, although this practice is not always accepted and is certainly regularly criticised. HE institutions can no longer live without heeding the expectations of the growing number of stakeholders, internal as well as external [25].

Most stakeholders no longer take for granted that higher education institutions by definition offer quality education. They all want a quality assurance system that fit the 'massification' higher education is witnessing currently, and institutions of higher learning must be accountable for what they do. While mass higher education is developing in Ghana, the effects of globalisation are becoming increasingly apparent. As [26] notes, the dimensions of globalisation are characterised by the growth of supranational organisations addressing policy and regulative subjects beyond the expanse of individual countries. Hence decisions taken by actors such as UNESCO, the OECD, and other international organisations, have far-reaching consequences for higher education institutions [27]. A rapid institutional and enrolment expansion amid financial stringency, frequent changes in policy directions, perceived decline in excellence in education, just to mention a few are the trends that raise concern about the quality of higher education leading to demands for quality assurance and accountability. 


\subsection{Quality Assurance and Higher Fashion Education in Ghana}

Fashion can be an aggregation of many things, from business to art to an attitude. As [28] puts it, fashion conjures up excitement and interest in all of us. Stone (2013) explains that fashion is the most dynamic of businesses and 'thrives on change, and change is the engine that fuels it' (p. 1). The fashion industry hence plays a vital role in delivering sustainable development. It does not just create jobs and contribute to the economy. It also has an enormous influence on society and the economy through its marketing, regular customer transactions, and complex, globalised supply chains [29]. The fashion world operates in a far different way today than in the past. It now moves faster and reaches more people. To understand the transformations that have occurred and will occur in the future, the dynamics that underlie the fashion business must be known [28].

The notion of fashion well exceeds the context of dress and embellishment. Fashion is also manifested in a wide range of other contexts such as architecture, furniture and automobiles which are material in nature. In order to appreciate the generalised theory of fashion, some definitions are appropriate. As [30] points out, the terms 'fashion' and 'clothing' tend to be used synonymously, but while fashion conveys many different social meanings, clothing is the generic raw materials of what a person wears. The term 'fashion' stands out from the other words, such as clothes, garment, attire, garb, apparel, and costume, often referred to in fashion. So what specifically is fashion? It is extremely challenging to give an exact definition of fashion because the word has different connotations throughout history.

[31] viewed fashion as nothing more or less than the prevailing style at any given time. [32] defined fashion as a series of recurring changes in the preferences of a group of people, which, though utility may accompany them, are not determined by it. In [33] perspective, fashion is a conception of what is currently relevant. According to [34], fashion, defined in its most general sense, is the pursuance of a novelty for its sake. [35] perceive fashion as a fundamental form of collective behaviour, whose coercive influence lies in the implied judgment of an anonymous multitude. [36] sees fashion as a process of social contagion by which the consumer adopts a unique style or product after the commercial introduction by the designer. [37] describes fashion as a demonstration of collective behaviour, and as such represents the current, accepted, prevailing style at any given time. [38] describes fashion as a social, economic and aesthetic force, and, more often than not, all three at the same time. Fashion according to [39], reflects and shapes contemporary culture. Fundamentally, these definitions illustrate the multifaceted and contradictory conceptualizations of the fashion phenomenon.

As mentioned earlier, quality assurance is a component of quality management and is focused on providing confidence that quality requirements will be fulfilled. Hence, higher education institutions that run vocational programs such as fashion are expected to establish quality assurance procedures, to carry out evaluations, appraise the effectiveness of their quality assurance procedures and examine the implementation of the conclusions of these procedures.

Considering the fact that qualifications and standards of education and training, such as fashion, have poor reputations for excellence, particularly in Africa and especially Ghana. The recognition of the quality of fashion education in general and its products is mostly not valued. In order to articulate the qualifications of fashion education with other qualifications, mechanisms must be put in place to guarantee quality, relevance, coherence consistency, and standards of their qualifications and programs. Fashion education is commonly perceived as a means of increasing employability of workers. Hence, there is less quality improvement. As a consequence, the role of government in fashion education can be regarded as a constant tension between products and employers and the perceptions of the government of the failure of fashion education to meet national economic needs and to contribute to the social objectives of employment in an optimal manner.

\section{Methodology}

Considering the objective of this investigation, collection and interpretation of data was carried out both quantitatively and qualitatively. Hence, a mixed methods strategy was employed. Polytechnic institutions are one segment in the Ghanaian higher education system that provides higher level fashion design education. Polytechnics offer three-year Higer National Diploma (HND) and Bachelor of Technology (Btech) in fashion design education. At present, there are ten (10) polytechnics with about 51,169 students on their HND programmes, and 871 on the B-tech programme [40]. For the purpose of the research study, the convenience sample was used to select four (4) polytechnics from the country. The use of convenience sampling was considered appropriate for the exploratory nature of the study [41]. The sample size in this research study was all HND fashion students as well as eight (8) polytechnic lecturers. Two (2) from each sampled Polytechnic.

\section{Findings}

\subsection{Responses from Students}

Table 1. Methods employed to improve quality of education.

\begin{tabular}{lll}
\hline Program & Freq.(n) & Percent(\%) \\
\hline Orientation Programs & 54 & 42.7 \\
Regular meeting with students & 29 & 23 \\
Publishing rules and policies of the department & 28 & 22.3 \\
Brochures & 15 & 12 \\
TOTAL & 126 & 100 \\
\hline
\end{tabular}

Respondents were requested to specify methods often employed to improve the quality of education in their various institutions. About $43 \%$ indicated the use of orientation 
programs in improving the quality of their education. While $23 \%$ specified the use of regular meetings, again, $22 \%$ of the total responses indicated the publication of rules and policies.
The least method used in improving the quality of education was brochures with 15 responses constituting $12 \%$.

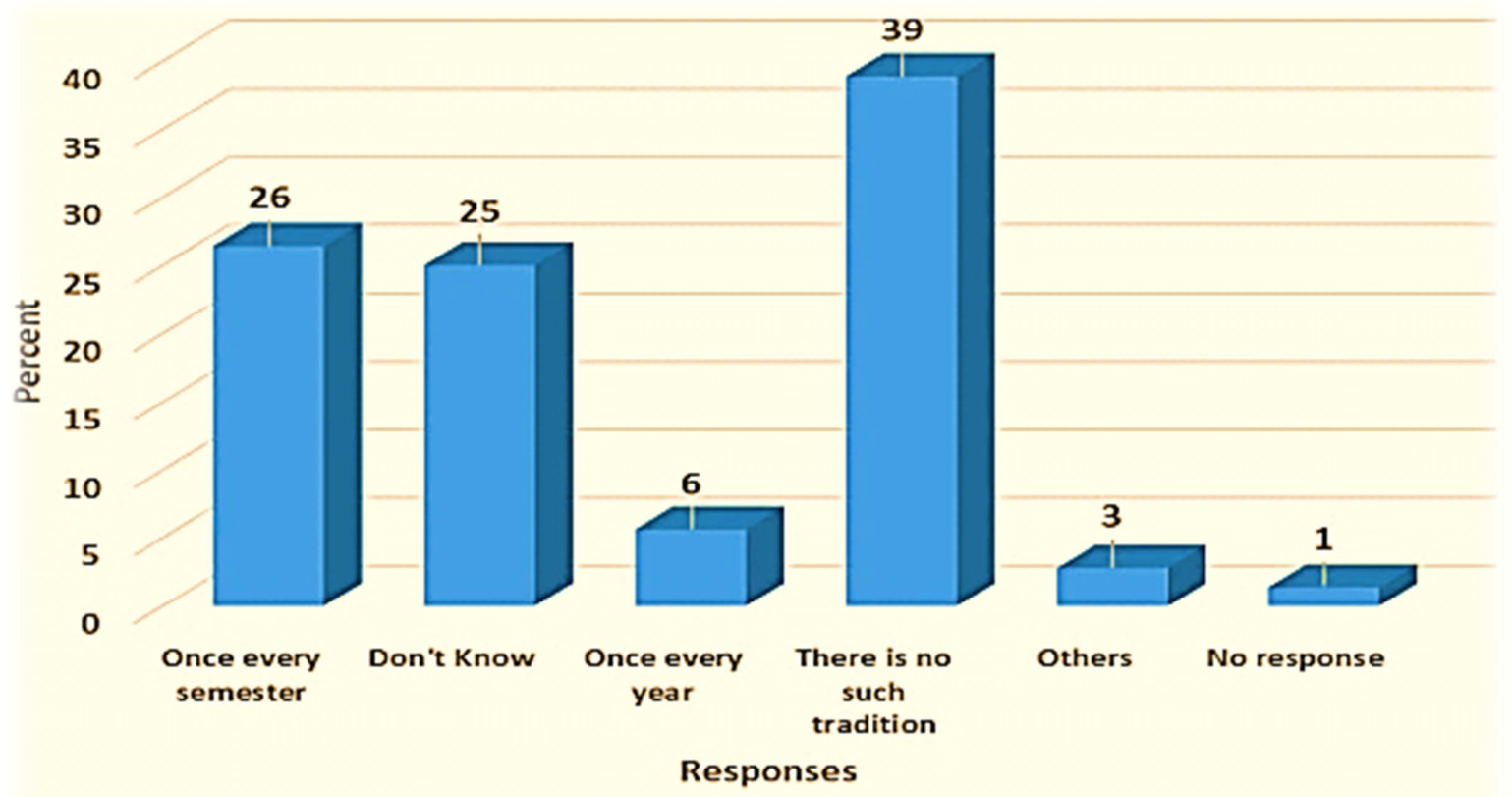

Convening meetings on issues of quality assurance

Figure 1. Rate of convening meetings with students to discuss issues concerning quality.

Students were asked to indicate how often meetings were convened to discuss issues concerning quality. The figure above demonstrates that there was no such thing in most of the institutions surveyed. However, $26 \%$ pointed out it was done once every semester, $25 \%$ did not know, and $6 \%$ noted it was done once every year.

Table 2. Faculty meeting on issues related to quality of education.

\begin{tabular}{|c|c|c|c|c|c|}
\hline & \multicolumn{4}{|c|}{ INSTITUTION } & \multirow{2}{*}{ Total } \\
\hline & $\mathbf{P}^{1}$ & $\mathbf{P}^{2}$ & $\mathbf{P}^{3}$ & $\mathbf{P}^{4}$ & \\
\hline \multirow{2}{*}{ Yes } & 3 & 3 & 12 & 1 & 19 \\
\hline & $8.3 \%$ & $30.0 \%$ & $75.0 \%$ & $11.1 \%$ & $26.8 \%$ \\
\hline \multirow{2}{*}{ No } & 33 & 7 & 4 & 8 & 52 \\
\hline & $91.7 \%$ & $70.0 \%$ & $25.0 \%$ & $88.9 \%$ & $73.2 \%$ \\
\hline \multirow{2}{*}{ Total } & 36 & 10 & 15 & 9 & 71 \\
\hline & $100.0 \%$ & $100.0 \%$ & $100.0 \%$ & $100.0 \%$ & $100.0 \%$ \\
\hline
\end{tabular}

$\chi 2=26.412, p=.001$

On the organisation of faculty meetings to discuss issues related to the quality of education, nearly two-thirds $(n=52$, $73.2 \%$ ) of the respondents indicated they are not involved in any faculty meetings on issues pertaining to the quality of education. However, 26.8\% responded 'Yes'. This demonstrates that most of the institutions surveyed do not convene or involve students relative to meetings on issues related to the quality of education. The results have been presented in relation to the institution of the respondents and chi-square analysis showed a statistically significant association between the two cross-tabulated variables (Pearson's chi-square=26.412, $\mathrm{p}<.05$ ).
Table 3. Departmental meeting on quality of education provision.

\begin{tabular}{|c|c|c|c|c|c|}
\hline & \multicolumn{4}{|c|}{ INSTITUTION } & \multirow{2}{*}{ Total } \\
\hline & $\mathbf{P}^{1}$ & $\mathbf{P}^{2}$ & $\mathbf{P}^{3}$ & $\mathbf{P}^{4}$ & \\
\hline \multirow{2}{*}{ Yes } & 6 & 1 & 16 & 0 & 23 \\
\hline & $17.1 \%$ & $10.0 \%$ & $100.0 \%$ & $.0 \%$ & $32.9 \%$ \\
\hline \multirow{2}{*}{ No } & 29 & 9 & 0 & 9 & 47 \\
\hline & $82.9 \%$ & $90.0 \%$ & $.0 \%$ & $100.0 \%$ & $67.1 \%$ \\
\hline \multirow{2}{*}{ Total } & 35 & 10 & 16 & 9 & 70 \\
\hline & $100.0 \%$ & $100.0 \%$ & $100.0 \%$ & $100.0 \%$ & $100.0 \%$ \\
\hline
\end{tabular}

$\chi 2=43.386, \mathrm{p}=.001$

Table 4. Completing questionnaires on efficiency/quality of lecturers.

\begin{tabular}{|c|c|c|c|c|c|}
\hline & \multicolumn{4}{|c|}{ INSTITUTION } & \multirow{2}{*}{ Total } \\
\hline & $\mathbf{P}^{1}$ & $\mathbf{P}^{2}$ & $\mathbf{P}^{3}$ & $\mathbf{P}^{4}$ & \\
\hline \multirow{2}{*}{ Yes } & 16 & 3 & 11 & 2 & 32 \\
\hline & $44.4 \%$ & $30.0 \%$ & $73.3 \%$ & $22.2 \%$ & $45.7 \%$ \\
\hline \multirow{2}{*}{ No } & 20 & 7 & 4 & 7 & 38 \\
\hline & $55.6 \%$ & $70.0 \%$ & $26.7 \%$ & $77.8 \%$ & $54.3 \%$ \\
\hline \multirow{2}{*}{ Total } & 36 & 10 & 15 & 9 & 70 \\
\hline & $100.0 \%$ & $100.0 \%$ & $100.0 \%$ & $100.0 \%$ & $100.0 \%$ \\
\hline
\end{tabular}

$\chi 2=7.631, p=.054$

Respondents were asked whether they were involved in departmental meetings on the provision of quality education. The responses confirm this is not done in most schools as more than half $(n=47,67.1 \%)$ of the respondents responded 'No'. 32.9\% responded 'Yes' to the question. The results have been presented in relation to the institutions of the respondents. Chi-square analysis of the results showed a statistically significant association between the institution 
and organising meetings on the provision of quality education (Pearson's chi-square $=43.386, \mathrm{p}<.05$ ).

Respondents were asked whether they complete questionnaires on the efficiency and quality of lecturers. From the results in Table 4, more than half $(n=38,54.3 \%)$ indicated they do not. However, $45.7 \%$ responded 'Yes' to completing questionnaires on efficiency/quality of lecturers in the institution. The results have been presented according to the institution of the respondents and chi-square analysis of the results specify that there was no statistically significant association between the institution of the respondents and completing questionnaires on the efficiency and quality of lecturers (Pearson's chi-square=7.631, $\mathrm{p}=.054$ ).

Table 5. Completing questionnaires on effectiveness of teaching and assessment.

\begin{tabular}{|c|c|c|c|c|c|}
\hline & \multicolumn{4}{|c|}{ INSTITUTION } & \multirow{2}{*}{ Total } \\
\hline & $\mathbf{P}^{1}$ & $\mathbf{P}^{2}$ & $\mathbf{P}^{3}$ & $\mathbf{P}^{4}$ & \\
\hline \multirow{2}{*}{ Yes } & 10 & 3 & 7 & 2 & 22 \\
\hline & $28.6 \%$ & $30.0 \%$ & $46.7 \%$ & $22.2 \%$ & $31.9 \%$ \\
\hline \multirow{2}{*}{ No } & 25 & 7 & 8 & 7 & 47 \\
\hline & $71.4 \%$ & $70.0 \%$ & $53.3 \%$ & $77.8 \%$ & $68.1 \%$ \\
\hline \multirow{2}{*}{ Total } & 35 & 10 & 15 & 9 & 69 \\
\hline & $100.0 \%$ & $100.0 \%$ & $100.0 \%$ & $100.0 \%$ & $100.0 \%$ \\
\hline
\end{tabular}

$\chi 2=2.089, p=.554$

It could be seen from Table 5 that, the majority $(n=47$, $68.1 \%$ ) of the respondents answered 'No' to being involved in completing questionnaires on the effectiveness of teaching and assessment in the institution. $31.9 \%$, on the contrary, stated 'Yes' to being involved in the activity. Chi-square analysis of the results $(\chi 2=2.089, p=.554)$ showed no statistically significant association between the responses on the involvement in completing questionnaires on the effectiveness of teaching and assessment and the institution of the respondents.

Table 6. Quality Assurance indicators in the Institutions.

\begin{tabular}{|c|c|c|c|c|c|}
\hline \multirow[b]{2}{*}{ Quality Indicators } & \multicolumn{4}{|c|}{ Institution } & \multirow{2}{*}{ Total } \\
\hline & $\mathbf{P}^{1}$ & $\mathbf{P}^{2}$ & $\mathbf{P}^{3}$ & $\mathbf{P}^{4}$ & \\
\hline \multicolumn{6}{|c|}{ Regular program/curriculum evaluation / review $(\chi 2=9.961, \mathrm{p}=.126)$} \\
\hline Yes & $16.1 \%$ & $11.1 \%$ & $44.4 \%$ & $22.2 \%$ & $20.7 \%$ \\
\hline No & $38.7 \%$ & $11.1 \%$ & $44.4 \%$ & $22.2 \%$ & $32.8 \%$ \\
\hline Do not know & $45.2 \%$ & $77.8 \%$ & $11.1 \%$ & $55.6 \%$ & $46.6 \%$ \\
\hline \multicolumn{6}{|c|}{ Assessment of learning outcomes $(\chi 2=10.664, p=.099)$} \\
\hline Yes & $67.6 \%$ & $87.5 \%$ & $100.0 \%$ & $55.6 \%$ & $74.6 \%$ \\
\hline No & $20.6 \%$ & $.0 \%$ & $.0 \%$ & $11.1 \%$ & $12.7 \%$ \\
\hline Do not know & $11.8 \%$ & $12.5 \%$ & $.0 \%$ & $33.3 \%$ & 12.7 \\
\hline \multicolumn{6}{|c|}{ Institutional self-assessment $(\chi 2=6.193, p=.402)$} \\
\hline Yes & $25.8 \%$ & $40.0 \%$ & $11.1 \%$ & $44.4 \%$ & $28.8 \%$ \\
\hline No & $41.9 \%$ & $40.0 \%$ & $33.3 \%$ & $11.1 \%$ & $35.6 \%$ \\
\hline Do not know & $32.3 \%$ & $20.0 \%$ & $55.6 \%$ & $44.4 \%$ & $35.6 \%$ \\
\hline \multicolumn{6}{|c|}{ Consultative meetings with students $(\chi 2=23.884 \mathrm{p}=.001)$} \\
\hline Yes & $17.6 \%$ & $11.1 \%$ & $90.9 \%$ & $22.2 \%$ & $30.2 \%$ \\
\hline No & $52.9 \%$ & $55.6 \%$ & $9.1 \%$ & $55.6 \%$ & $46.0 \%$ \\
\hline Do not know & $29.4 \%$ & $33.3 \%$ & $.0 \%$ & $22.2 \%$ & $23.8 \%$ \\
\hline \multicolumn{6}{|c|}{ External evaluation $(\chi 2=14.051, \mathrm{p}=.029)$} \\
\hline Yes & $48.5 \%$ & $70.0 \%$ & $.0 \%$ & $22.2 \%$ & $40.3 \%$ \\
\hline No & $27.3 \%$ & $10.0 \%$ & $40.0 \%$ & $22.2 \%$ & $25.8 \%$ \\
\hline Do not know & $24.2 \%$ & $20.0 \%$ & $60.0 \%$ & $55.6 \%$ & $33.9 \%$ \\
\hline
\end{tabular}

Table 6 presents an overview of the results regarding the responses on Quality Assurance indicators in the various institutions studied. Concerning regular program/curriculum evaluation or review, it could be observed that majority of the students indicated they 'Do not know' anything about it. While 32.8\% indicated 'No'. The results again have been presented in relation to the institution of the respondents. Chi-square analysis revealed no statistically significant relationship between the institution and the responses to the question (Pearson's chi-square $=9.961, \mathrm{p}=.126$ ).

On the assessment of learning outcomes as a Quality Assurance tool, the results from the table show about twothirds responding 'Yes' to assessing learning outcomes in the institution. However, $12.7 \%$ stated 'No' to that effect. The results have been cross-tabulated by the institution of the respondents, and chi-square analysis of the results revealed that there was no statistically significant association between the institution and the responses to the assessment of learning outcomes (Pearson's chi-square=10.664, $\mathrm{p}=.099$ ).

The respondents were further asked whether there is an institutional self-assessment. The responses in Table 2 indicate $35.6 \%$ responding 'No'. While $35.6 \%$ stated they 'do not know' as to whether their institutions do institutional self-assessments. However, only $28.8 \%$ stated 'Yes'. The results have again been presented according to the institution of the respondents and chi-square analysis of the results showed no statistically significant association between responses on institutional self-assessment and the institution of the respondents (Pearson's chi-square $=6.193, \mathrm{p}=.402$ ).

Regarding consultative meetings with students, the results demonstrate that most of the institutions do not consult with students as $46 \%$ of the respondents responded 'No'. However, $30.2 \%$ of the respondents responded 'Yes'. It is worth noting that $23.8 \%$ of the respondents 'do not know' about any consultative meetings convened with students. The responses have been disaggregated by the institution of the respondents. Chi-square analysis of the responses showed no statistically significant association between responses on consultative meetings with students and the institution of the respondents (Pearson's chi-square $=23.884, \mathrm{p}<.05$ ).

On the issue of external evaluation, the results from Table 2 indicate $40.3 \%$ of the respondents responding 'Yes' to having an external evaluation in the institution while $33.9 \%$ stated they do not know. On the contrary, $25.8 \%$ of the respondents stated 'No' to the fact that their institutions employ external evaluation. The results have been presented in relation to the institution of the respondents and chi-square analysis of the results showed a statistically significant association between the responses on external evaluation and the institution of the respondents (Pearson's chisquare $=14.051, \mathrm{p}<.05$ ).

\subsection{Responses from Staff}

This segment presents the analysis of quantitative data on staff members of the various institutions. To this end, staff was asked about their views regarding systems and practices as well as the challenging factors in Quality Assurance. They rated among a list of factors on a five-point rating scale 
(strongly disagree $=1-5=$ strongly agree). Then mean scores were compared to determine the respondents' perceived importance of each factor.

\subsubsection{Quality Assurance Methods and Procedures}

The results indicated that most staff members were optimistic about the impact of quality assurance both internal and external. To the question, to what degree do you agree with the various perceptions of quality in education, $48.2 \%$ of the respondents said they strongly agreed with all the options given [Quality as value for money; fitness for purpose; as excellence; as perfection; as a transformation of the learner; and quality leads to high-quality human resource development]. $37.6 \%$ said they agreed with all $14.2 \%$ specified they were not sure.

To the question, who are the main actors in the pursuit of Quality Assurance practices, 38.1\% of the respondents said Quality assurance agencies, 21.3\% indicated lecturers and students, and $18.7 \%$ said departments, faculties and departments, and $21.9 \%$ indicated everyone must be involved. To the question, does your faculty/institution have Quality Assurance policies in place, $87.4 \%$ of respondents answered positively, while $12.6 \%$ gave a negative evaluation.

When asked to evaluate the stage of implementation of Quality Assurance in their faculties/institutions the following were their answers; [setting quality indicators/standards for teaching and learning across all programs], 11.2\% said 'Yes' they have implemented, $12.5 \%$ stated that they are currently implementing, $26.4 \%$ indicated they are planning to implement $38.8 \%$ responded they do not have anything like that. The rest $11.1 \%$ did not provide a response. [Developing quality assessment manual/ guidelines], 13.3\% said 'Yes' they have implemented, $11.6 \%$ stated that they are currently implementing, $19.8 \%$ indicated they are planning to implement $37.4 \%$ responded they do not have anything like that. The rest $17.9 \%$ did not respond to the question.

On [Setting institutional structure and responsibility for quality improvement], $11.9 \%$ said they have implemented, $17.5 \%$ stated that they are currently implementing, $21.3 \%$ indicated they are planning to implement $39.2 \%$ responded they do not have anything like that. The rest $10.1 \%$ did not respond at all to that question. [Providing guidelines, procedures and support to academic staff to ensure the quality of their teaching], $18.5 \%$ said 'Yes' they have implemented, $20.3 \%$ said they are currently implementing, $33.8 \%$ indicated they are planning to implement $27.4 \%$ responded they do not have anything like that.

On [Conducting regular review of the study programs \& curriculum], $13.7 \%$ said they have implemented, $17.5 \%$ said they are currently implementing, 33.3\% indicated they are planning to implement $29.7 \%$ responded they do not have anything like that. The rest $5.8 \%$ did not respond at all to the question. [Conducting regular staff meetings to discuss quality of education and student learning], 11.6\% said they have implemented, $26.3 \%$ stated that they are currently implementing, $32.5 \%$ indicated they are planning to implement $19.8 \%$ responded they do not have anything like that. The rest $9.8 \%$ did not provide any response. [Using results of program/course review for improvement of student learning], $29.3 \%$ said they have implemented, $21.8 \%$ said they are currently implementing, $37.3 \%$ indicated they are planning to implement $11.6 \%$ responded they do not have anything like that.

According to respondents, both internal and external factors influence the adoption and implementation of accepted QA. Internally, ineffectiveness in leadership, lack of staff and student capacity, the absence of staff and student engagement and commitment, inadequacy and improper utilization of resources, student learning environment/experience, absence of a supportive professional quality culture, program and curriculum relevance and illequipped laboratories and libraries are the major challenges facing the implementation and practice of QA in almost all the institutions.

\subsubsection{Quality Indicators}

The majority of staff members in the various institutions rated institutional mission and educational goals; teaching, learning and assessment processes; Governance \& Management; Learning environment (Infrastructure \& learning resources); Program relevance \& curriculum as an essential area of achieving quality. The rest varied between essential and not essential; student admission and support services; student progression; academic and support staff; high alumnae employment and student learning experience.

Responses from staff members about the extent to which existing Quality Assurance systems (policy, models, guidelines, methods and instruments) communicated or helpful in their faculties, the following were their answers; Minority, 28.4\% indicated that, to a very large extent, these are communicated to them but to a very small extent related to the quality of student learning.

Most staff members also indicated that the QA systems to a large extent are helpful in enhancing the quality of teaching and assessment practices. They again stated that the QA systems to a little extent are helpful in response to external issues and changes occurring within it. (e.g. Technology, globalisation, etc.). $58 \%$ of the respondents specified that, to a very large extent, QA systems match internal capabilities and external possibilities of their faculty/department.

To the question, in which areas does your institution use/require quality indicators, $32 \%$ indicated they require general academic performance; students' performance and facilities for teaching always, $29.9 \%$ said they need facilities for research; general academic performance; research performance and workforce development very often. $41.4 \%$ specified they require general academic performance; the ability of alumnae to be employed and workforce development sometimes.

When asked how they evaluate the impact of QA practices on the improvement of everyday teaching and learning in their faculty, $46.1 \%$ rated it very high, $32.4 \%$ high. The rest were not sure on how to rate it. 


\subsubsection{Challenges Faced in Quality Assurance in Higher Fashion Education}

When asked to indicate in their opinion factors militating against QA in their institution, 68.8\% agreed strongly to accelerating change which is presenting complex problems relative to QA; inadequate Resources; institutional commitment and support for quality; external quality regulation requirements and expectations; bureaucratic complexity of the review process; rapid globalization, impacts of technology, movement of students and staff, across borders; variances between internal QA practices and accepted practices as well as population explosion; illequipped libraries and overcrowded lecture halls.

About $46.3 \%$ of the responses varied between agreeing and not sure to QA in place in the institution not equivalent to accepted practices elsewhere; variances between internal QA practices and accepted practices; accreditation standards not linked to outcomes and skills needed by labour market; institutional commitment and support for quality; insufficient communication within institutions' on external QA processes; rapid globalization, impacts of technology, movement of students and staff, across borders and achievement which is now measured by credits, academic performance; ill-equipped libraries; laboratories do not have essential apparatus; commitment and engagement of students for their learning; population explosion and overcrowded lecture halls.

In addition to $23.8 \%$ disagreed with the lack of incentives and sanctions to enforce compliance; commitment and engagement of students in their learning; achievement which is now measured by credits, academic performance and qualifications awarded; bureaucratic complexity of the review process; inability to meet stakeholders' expectations; unpredictable academic calendar owing to the constant strikes by staff. When asked to evaluate the strategies which have the likelihood of mitigating QA challenges, $71.4 \%$ specified it is very likely that assessment \& regular program/curriculum evaluation/review; institutional self assessment \& proper monitoring; assessment of learning outcomes/Student evaluation; improved funding; provision of research grants to lecturers and conducive teaching/learning environment will mitigate QA challenges. While 20.3\% indicated that training and retraining of lecturers; adequate provision of required infrastructure \& functional facilities; SWOT analysis; right number of qualified and competent educators; appropriate and teaching methods/strategies might mitigate QA challenges. Again, 8.6\% were not sure on public - private partnership; the right number of qualified; competent educators; adequate and teaching methods/strategies and conducive teaching/learning environment will mitigate QA issues.

\subsection{Conclusions from Interviews}

The conclusion drawn from interviews suggests that qualification, competence, and motivation of the teaching staff across all the institutions were weak. Academic staff across all the institutions were not properly trained, motivated and engaged to face challenges and improve the quality of education to the level it should be. Although there are differences in the qualification mix of staff, shortage of qualified and experienced staff is a feature across all the institutions studied. It can also be concluded that most higher education institutions seem to perceive quality assurance as an input - all resources that include people, facilities, technology and funding needed for the entire process of education - of an education system, with little attention paid to process, outputs and outcomes. This standpoint on quality assurance essentially misinforms higher education institutions and instead of focusing on the process of how to achieve the right quality based on their current situations they concentrate on irrelevant issues.

The unavailability of resources for quality assurance processes is one major challenge across the all the institutions studied. Also, internally, findings indicate that the leadership of the institutions may not be influential in enforcing actual quality assurance mechanisms. Again, there is no link and shared vision among all involved regarding setting directions and goals to ensure quality in the various institutions. Ensuring quality assurance in institutions requires the capability, engagement, and commitment to both staff and students. However, the results are contrary. Again, institutions do not have an established framework or quality management. Any model that will bring about efficiency, effectiveness and betterment in quality assurance practices in the higher education institutions is vital. The old ways of doing things persist and this suggests that the adoption and implementation of quality assurance without changing the minds of the people involved will not result in any significant transformation. Knowledge of quality assurance is also not widely shared in the institutions, hence are no clear perspectives on it.

\section{Conclusion}

The findings in this study provided valuable insights regarding the current issues relative to quality assurance in higher education institutions. Firstly, this study has revealed that establishing quality assurance systems and policies is not a guarantee to solving quality issues in higher fashion education because enabling factors in both the internal and external environment were absent. It may be argued that given the rapidly growing demand for higher education, rapid expansion is inevitable. However, the concern here is how the institutions can address access without compromising quality. With a different approach, higher fashion education can discover what they can do that is new, and how best to do it, thus find itself not just navigating tomorrow's global trends, but shaping them. Even though governance and management appear similar in meaning, Ghanaian higher fashion education requires significant reforms in both. If Ghanaian higher fashion education is to respond to the contemporary quandary, it needs to undergo drastic changes in its governance and management. Simply put, Ghanaian higher fashion education needs a paradigm shift. 


\section{Recommendations}

It is recommended that internally since lecturer quality is one pillar of quality education, higher fashion education institutions must lay out a system that is capable of attracting the best lecturers with industry practice who are competent, motivated and committed. Moreover, this demands leadership's capacity to plan and execute this. Also, adequate resources and a supportive culture for student learning must be ensured. Furthermore, the quality assurance systems must be institutionalised, accepted and owned by the academia.

Additionally, fifty years after independence, Ghana's higher education system has made significant strides, but now needs strides that can improve and assure quality. Again, the various higher fashion education institutions must consciously plan for quality as quality in higher education can be delivered, hand in hand with increasing accessibility without any compromise. These can be achieved by putting minimum criteria on quality. Also, if quality assurance must remain a priority, it is important that $\mathrm{NAB}$ and the HE institutions shift the focus from a procedural check to the development of a real quality assurance culture. Finally, quality assurance processes must always involve students, as students are the primary and final clients of the education process.

\section{References}

[1] Ebuara, V. O. (2012). Quality Control Measures and Sustainable Development in Higher Education System in Cross River State, Nigeria. Journal of Education and Practice 3 (7), 81-95.

[2] UNESCO (2013). Quality Assurance in Higher Education. Education Sector Technical Notes http://unesdoc.unesco.org/images/0022/002221/222126e.pdf:

[3] Tsevi, L. (2014). Private Higher Education's Quality Assurance in Ghana. International Higher Education, Vol. 75, 22-24.

[4] Azameti, M. S. \& Adjei, E. (2013). Academic Assessment of Students Work and Quality Assurance in Education. International Journal of Scientific Research in Education, 6 (1), $1-8$.

[5] Badu-Nyarko, S. (2013). Quality assurance measures in distance learning at University of Ghana. African Educational Research Journal Vol. 1 (2), 126-133.

[6] Utuka, G. (2011). Demonstrating quality: Evaluation of institutional and programme accreditation in Ghana. International Journal of Vocational and Technical Education, 3 (8), 135-142.

[7] Baryeh Obeng Boampong, J. (2009). Higher Education Quality Assurance in Ghana How NAB is coping with the Balance between Improvement and Accountability. Norway: Institute of Educational Research.

[8] Pillay, H. \& Kimber, M. (2009). Quality assurance in higher education: For whom and of what? Journal of Management Education, 3 (3), 270-281.

[9] Ansu, Y. (2007) Higher Education Quality Assurance in SubSaharan Africa Status, Challenges, Opportunities, and Promising Practices. In Materu, P. Higher Education Quality
Assurance in Sub-Saharan Africa Status, Challenges, Opportunities, and Promising Practices. Africa Region Human Development Department Washington, D.C.: World Bank Working paper no. 124.

[10] Altbach, P. G., Reisberg, L. \& Rumbley. L. E. (2009). Trends in Global Higher Education: Tracking an Academic Revolution. France: A Report Prepared for the UNESCO 2009 World Conference on Higher Education.

[11] UNESCO Institute for Statistics (UIS) (2011). Quebec: UNESCO-UIS.

[12] Okebukola, P. A. O. (2011). Emerging Regional Developments and Forecast for Quality in Higher Education in Africa. Presented at the 2014 CHEA International Quality Group Annual Conference, Washington DC, USA, January 29-30.

[13] Pongo, N. A., Obeng Asare, T. \& Abdul-Fatahi, I. (2015). Evaluation of the Challenges of 21 st Century on Quality Assurance of Higher Fashion Education in Ghana. International Institute for Science, Technology \& Education, Vol. 29, 18-28.

[14] Smith, W. (2011). The Paradigm Shift in Higher Education: A Call for Action. Speech delivered at Annual Conference of the Association of Caribbean Higher Education Administrators (ACHEA). UWI Cave Hill Campus, Barbados.

[15] Picker, L. (2014). The Economic Decline in Africa. UK: The National Bureau of Economic Research.

[16] Artadi, E. V. \& Sala-i-Martin, X. (2003). The Economic Tragedy of the $\mathrm{XX}^{\text {th }}$ Century: Growth in Africa Working Paper 9865 http://www.nber.org/papers/w9865 National Bureau of Economic Research. Cambridge: NBER.

[17] Wells, J. P. (2014). The DNA of a Converging Diversity: Regional Approaches to Quality Assurance in Higher Education. Washington DC: Council for Higher Education Accreditation (CHEA).

[18] Weber, L. (2010). Quality Assurance in Higher Education: A Comparison of Eight Systems. World Bank Europe and Central Asia Knowledge Brief, 35, 62251.

[19] Irby, D. M., Cooke, M. \& O'Brien, B. C. (2010). Calls for Reform of Medical Education by the Carnegie

[20] Triplett, J. (2009). Health System Productivity. Oxford Handbook of Health Economics.

[21] McPherson, P. \& Shulenburger, D. (2010). Understanding the Cost of Public Higher Education Planning for Higher Education, 38 (3), 15-24.

[22] World Bank (2013). Tertiary education in Africa. Education in Sub-Saharan Africa: http://go.worldbank.org/K09Q14BTT0

[23] Vaira, M. (2007). Quality assessment in higher education: an overview of institutionalisation, practices, problems and conflicts. In Quality Assessment for Higher Education (ed.) Cavalli, A. Italy: Portland Press Ltd.

[24] Amaral, A. \& Magelhães, A. (2002). The emergent role of external stakeholders in European higher education governance. In Governing Higher Education: National Perspectives on Institutional Governance (Amaral, A., Jones, G. A. and Karseth, B., eds), pp. 1-21, Kluwer Academic Publishers, Dordrecht. 
[25] McBurnie, G. (2001) Leveraging globalisation as a policy paradigm for higher education. Higher Education in Europe $26(1), 11-26$.

[26] De Wit, K. \& Verhoeven, J. C. (2001). The higher education policy of the European Union: with or against the member states. In Higher Education and the Nation State: The International Dimension of Higher Education (Huisman, J., Maassen, P. and Neave, G., (Eds), pp. 175-231, Pergamon, Oxford.

[27] Stone, E. (2013). The dynamics of fashion. Canada: Bloomsbury Publishing Inc.

[28] Forum for the Future (2010). Fashion Futures 2025: Global Scenarios for a Sustainable Fashion Industry. London: Overseas House.

[29] Kawamura, Y. (2005). Fashion-ology: An Introduction to fashion studies. New York: Berg Publishers Ltd.

[30] Nystrom, P. H. (1928). Economics of Fashion. New York: The Ronald Press Company

[31] Hurlock, E. (1929). The psychology of dress: An analysis of fashion and its motive. New York: The Ronald Press Co.

[32] Daniels, A. H. (1951). Fashion merchandising. Harvard Business Review, Vol. 29, 51-60.
[33] Robinson, D. E. (1958). Fashion theory and product design. Harvard Business Review, Vol. 36, 126-138.

[34] Lang, K. and Lang, G. (1961). Collective dynamics. New York: Thomas Y. Crowell.

[35] King, C. W. (1964). The innovator in the fashion adoption process. In Smith, L. G. (Ed.), Reflections on progress in marketing. Chicago: American Marketing Association.

[36] Horn, M. J. (1968). The second skin. Boston: Houghton Mifflin.

[37] Finkelstein, J. (1996). After a fashion. Carlton: Melbourne University Press.

[38] Arnold, R. (2009). Fashion: A very short introduction. Oxford: Oxford University Press.

[39] National Accreditation Board (NAB) (2015). Tertiary Education Statistics Report: Composite Statistical Report on all Categories of Tertiary Educational Institutions in Ghana for the 2012/2013 Academic Year. NAB, Accra.

[40] Zikmund, W. G. (2003). Business Research Methods. (7th ed.), Mason: South-Western. 